\title{
Update of the Texaco mortality study 1947-93: part II. Analyses of specific causes of death for white men employed in refining, research, and petrochemicals
}

\author{
Barbara J Divine, Christine M Hartman, Judy K Wendt
}

\begin{abstract}
Objective-To examine patterns of mortality for specific causes of death with increases in the Texaco mortality study to determine if the patterns are related to employment in the petroleum industry. Methods-Mortality patterns by duration of employment in various job groups were examined for mesothelioma, nonHodgkin's lymphoma, multiple myeloma, cell type specific leukaemia, and brain tumours.
\end{abstract}

Results-Mortality from mesothelioma was examined for the total cohort and for two maintenance groups with the greatest potential for exposure to asbestos. The insulator group had a standardised mortality ratio (SMR) of 3029, and a larger group consisting of insulators, carpenters, labourers, electricians, pipefitters, boilermakers, and welders had an SMR of 411. The mortalities from mesothelioma increased with increasing duration of employment. Mortality was lower for those first employed after 1950. An analysis of all brain tumours for the total cohort and some job and unit subgroups resulted in an SMR of 178 for those employed on the units related to motor oil and 166 for those employed as laboratory workers. Mortality from brain tumours in both of these job groups was higher for those employed $\geqslant 5$ years in the group. An analysis of nonHodgkin's lymphoma showed no consistent patterns among the various employment groups. Mortality from multiple myeloma was non-significantly increased among people employed on the crude $(S M R=155)$ and fluid catalytic cracking units $(S M R=198)$. Leukaemia mortality was not increased for the total cohort, and a cell type analysis of leukaemia mortality for the total cohort showed no significant increases for the major cell types. However, there were significant increases for acute unspecified leukaemia $(S M R=276)$ and leukaemia of unknown cell type $(\mathrm{SMR}=231)$.

Conclusions-Analyses of specific causes of death by duration of employment in various job and process units did not show any patterns which suggest that, other than for mesothelioma, any of these increases in mortalities were likely to have resulted from workplace exposures or from employment at one of the places included in the Texaco mortality study. (Occup Environ Med 1999;56:174-180)

Keywords: petroleum industry; mesothelioma; asbestos; non-Hodgkin's lymphoma; multiple myeloma; brain tumours

A recent report presented the 1947-93 patterns of mortality for the workers of the Texaco mortality study employed for $\geqslant 5$ years at company refineries, petrochemical plants, and research laboratories. ${ }^{1}$ The study cohort consisted of over 28840 workers, and the results showed that the overall mortality and most cause specific mortalities were lower than those of the general United States population. The patterns of mortality for the job and process units were similar to those for the overall cohort. However, there were a few increases that were found consistently in several of the analysis subgroups, were significantly increased, or have been found in other studies of petroleum industry workers.

Significant increases for cancer of other lymphatic tissue, which includes both lymphoma and multiple myeloma, were reported in the earlier study of workers employed on the fluid catalytic cracking unit and on the crude stills. Non-significant increases were also found for several other job and unit combinations. Mortality from non-Hodgkin's lymphoma and multiple myeloma were examined separately to reflect more recent classifications of these diseases.

The total cohort of white men showed a significant excess for benign and unspecified neoplasms, and the excess was also noted in some of the job and unit analyses, especially for those ever employed in laboratories or on the motor oil units. Twenty one of the 41 deaths in the benign and unspecified neoplasm category were from benign and unspecified neoplasms of the brain. Brain cancer mortality was also increased for those ever employed in laboratories or on the motor oil units. Therefore, further analyses of all brain tumours (malignant, benign, and unspecified combined) by job and unit combinations were carried out.

A recent publication by Tsai et al showed that a group of maintenance workers defined by their potential for exposure to asbestos had a significant excess of mesothelioma. Therefore, it was decided to examine mortality from 
mesothelioma for several job groups with the potential for exposure to asbestos.

An investigation of the mortality for leukaemias of specific cell types was also performed. Refinery workers have the potential to be exposed to benzene which has been associated with an increased risk of acute myelogenous leukaemia at high exposure levels. ${ }^{3}$ Wong and Raabe $^{4}$ recently conducted a meta-analysis of leukaemia by cell type in petroleum industry cohorts but found no significantly increased risks for any cell type, including acute myelogenous leukaemia. Satin et a $\bar{l}$ found an excess of acute lymphocytic leukaemia in a recent cohort mortality study at a large refinery next to the largest factory included in the Texaco mortality study. However, there was no exposureresponse relation, and the authors also found a large deficit for chronic lymphocytic leukaemia.

\section{Methods}

The expected numbers of deaths were obtained by multiplying the person-years for each subgroup analysed by the United States mortalities. Standardised mortality ratios (SMRs) were calculated as the ratio of the observed and expected numbers of deaths for specific causes multiplied by 100 . The SMRs were tested for statistical significance with Poisson based $95 \%$ confidence intervals (95\% CIs) assuming a two sided test. The SMRs were calculated for those people ever employed in the job and unit group of interest, and if there were sufficient numbers of deaths, for those people who were employed in the job and unit group for $\geqslant 5$ years. The SMRs were also calculated by the period in which first employment occurred.

ANALYSIS OF DEATHS FROM MESOTHELIOMA Mesothelioma does not have a specific code in the eighth revision of the international classification of diseases (ICD-8) that can be used to identify the deaths from this cause. Instead, depending on the phrasing of the death certificate, mesothelioma can be coded as a respiratory cancer (ICD-8 codes 162.1, 163, 163.0, or 163.9), a malignant neoplasm without mention of site (ICD-8 codes 199, 199.0, or 199.1), a benign respiratory disease (ICD-8 codes $212.3,212.4$, or 228), or a malignant neoplasm of the peritoneum (ICD-8 code 158). Death certificates for the Texaco mortality study cohort with any of these ICD-8 codes either as the underlying or as a contributory cause of death were reviewed. Those death certificates with any mention of mesothelioma were defined as a case.

Because mortalities for mesothelioma have not been published, the 1973-80, 1985-8, and 1988-91 surveillance, epidemiology, and end results programme of the National Cancer Institute mesothelioma incidences were used. As mesothelioma is almost always fatal, the incidences were assumed to be the same as the mortalities. It was assumed that the rates in the 1950 s and 1960s were one quarter and one half, respectively, the rates for the 1970s. These assumptions were the same as those used for the recent report by Tsai et $a l^{2}$ and are based on the pattern of incidences from the Connecticut tumour registry. ${ }^{6}$

Mortality from mesothelioma for the total cohort of white men was examined as well as the mortality in two job groups with the greatest potential for exposure to asbestos. The first job group consisted of people ever employed as insulators. The second group included people ever employed as insulators, pipefitters, welders, boilermakers, carpenters, electricians, and labourers, a grouping similar to that reported recently. ${ }^{2}$ The mesothelioma patterns were examined for these groups by duration of employment and by time first employed in the job group.

ANALYSIS OF LYMPHOHAEMATOPOIETIC DEATHS The combined categories of lymphohaematopoietic cancers in the published United States mortalities prevented analyses of these causes of death as separate entities. For example, lymphosarcoma and reticulum cell sarcoma comprise one category, whereas multiple myeloma, lymphoma, and polycythemia vera are grouped in another category. Haematologists recommend that lymphosarcoma and reticulum cell sarcoma should be grouped with lymphoma to make a non-Hodgkin's lymphoma category and that the other causes of lymphohaematopoietic cancers should be examined separately (Irons R, 1995; personal communication). Also, all of the leukaemias are grouped together in the published United States mortalities although the different cell types are different diseases and can have different aetiologies.

Mortalities for the period 1964-92 for multiple myeloma, leukaemia by cell type, and lymphoma were obtained from the mortality and population data system maintained by the University of Pittsburgh Department of Biostatistics. ${ }^{7}$ The rates for the years before 1964 were assumed to be the same as those for 1965-9. The rates for unspecified leukaemia for the years 1980-92 were assumed to be the same as those for 1975-9. The rates for lymphosarcoma and reticulum cell sarcoma from Monson's program ${ }^{8}$ were added to the lymphoma rates to give mortalities for nonHodgkin's lymphoma. The mortalities for each of the causes of death of interest were then multiplied by the person-years for the subgroups to give the expected numbers of deaths for the specific cause of interest.

ANALYSIS OF DEATHS FROM BRAIN TUMOURS

Because several of the deaths from benign and unspecified neoplasms in the previous report on this cohort ${ }^{1}$ were categorised as benign and unspecified brain tumours, United States mortalities for these two categories of death were also obtained from the University of Pittsburgh mortality and population data system. The rates were added together, and the rates for the years before 1964 were assumed to be the same as those for 1965-9. These rates were then multiplied by the person-years for the various groups of interest. Observed and expected numbers of deaths from brain tumours were added to those for cancer of the brain and 
Table 1 Texaco mortality study: SMRs for mesothelioma and lung cancer, white men, 1947-93

\begin{tabular}{|c|c|c|c|c|c|c|c|}
\hline \multirow[b]{3}{*}{ Total cohort } & \multicolumn{4}{|c|}{ Mesothelioma } & \multicolumn{3}{|c|}{ Lung cancer } \\
\hline & \multirow{2}{*}{$\begin{array}{l}\text { Observed } \\
44\end{array}$} & \multirow{2}{*}{$\begin{array}{r}S M R \\
297\end{array}$} & \multicolumn{2}{|l|}{$95 \% C I$} & \multirow{2}{*}{$\begin{array}{l}\text { Observed } \\
537\end{array}$} & \multirow{3}{*}{$\frac{S M R}{67}$} & $95 \% C I$ \\
\hline & & & 216 to & 399 & & & 61 to 73 \\
\hline Insulators (duration of employment): & & & & & & & \\
\hline 0 to $4 \mathrm{y}$ & 4 & 571 & 153 to & 1462 & 31 & 77 & 52 to 110 \\
\hline 5 to $19 \mathrm{y}$ & 1 & 714 & 9 to & 3974 & 10 & 133 & 63 to 245 \\
\hline$\geqslant 20 \mathrm{y}$ & 10 & 9916 & 447 to & 18237 & 7 & 128 & 51 to 264 \\
\hline Before 1950 & 9 & 4586 & 2092 to & 8706 & 18 & 159 & 94 to 251 \\
\hline 1950 And after & 2 & 1200 & 134 to & 4335 & 5 & 61 & 20 to 141 \\
\hline $\begin{array}{l}\text { Insulators, pipefitters, welders, labourers, boilermakers, } \\
\text { electricians, carpenters (duration of employment): }\end{array}$ & 29 & 411 & 275 to & 590 & & & \\
\hline 0 to $4 \mathrm{y}$ & 14 & 239 & 131 to & 402 & 219 & 68 & 59 to 78 \\
\hline 5 to $19 \mathrm{y}$ & 7 & 322 & 129 to & 664 & 91 & 75 & 60 to 92 \\
\hline$\geqslant 20 y$ & 16 & 1053 & 601 to & 1710 & 75 & 89 & 70 to 112 \\
\hline Before 1950 & 25 & 470 & 304 to & 694 & 238 & 78 & 69 to 89 \\
\hline 1950 And after & 4 & 230 & 62 to & 591 & 52 & 61 & 45 to 80 \\
\hline
\end{tabular}

central nervous system to calculate an overall brain tumour SMR. The SMRs were calculated for the total cohort and for the job and unit groups where increased SMRs for either brain cancer or benign and unspecified neoplasms were found in the overall analysis. ${ }^{1}$

\section{Results}

MORTALITY ANALYSES OF MESOTHELIOMA

There were 44 deaths with any mention of mesothelioma on the death certificate. For all but one of these, mesothelioma was the underlying cause of death. All but eight of the decedents were first employed before 1 January 1950, and for all, at least 30 years had elapsed between the time they were first employed and the date of death. The mesothelioma SMR for the total cohort was 297 which was significant. There were 11 deaths from mesothelioma for those employed as insulators for $\geqslant 1$ year $(\mathrm{SMR}=3029,95 \% \mathrm{CI} 1510$ to 5420$)$ and 29 deaths for those employed as insulators, pipefitters, welders, labourers, boilermakers, electricians, or carpenters for $\geqslant 1$ year (SMR $=411,95 \%$ CI 275 to 590).

Table 1 shows the SMRs for mesothelioma for all white men and for the two exposure groups by duration of employment in the group and by time first employed. Almost all of the SMRs were significantly increased and corresponded with increasing duration of employment in each group. The highest SMRs are found among people employed as insulators for $\geqslant 20$ years (SMR=9916). The SMRs were higher for people first employed in either of the job groups before 1950. Increased SMRs were

Table 2 Texaco mortality study: SMRs for brain tumours, white men, 1947-93

\begin{tabular}{lllll}
\hline & Observed & Expected & SMR & 95\% CI \\
\hline $\begin{array}{llll}\text { Total cohort: } \\
\quad \text { Ever }\end{array}$ & 85 & 75 & 113 & 90 to 140 \\
$\quad$ Employed before 1950 & 62 & 54.8 & 113 & 86 to 145 \\
$\quad$ Employed 1950 and after & 23 & 20.2 & 113 & 72 to 170 \\
$\begin{array}{l}\text { Maintenance: } \\
\quad \text { Ever }\end{array}$ & 61 & 55.1 & 110 & 84 to 142 \\
$\quad \begin{array}{l}\text { Laboratory staff: } \\
\quad \text { Ever }\end{array}$ & 19 & 11.4 & 166 & 99 to 259 \\
$\quad$ Employed $\geqslant 5$ y & 15 & 8.1 & 185 & 103 to 305 \\
$\quad \begin{array}{l}\text { Receiving, pumping, and storage: } \\
\quad \text { Ever }\end{array}$ & 11 & 10.9 & 101 & 50 to 181 \\
$\begin{array}{l}\text { Pipefitter } \\
\quad \text { Ever }\end{array}$ & 15 & 14.9 & 100 & 56 to 165 \\
$\quad \begin{array}{l}\text { Motor oil unit: } \\
\quad \text { Ever }\end{array}$ & 11 & 6.2 & 178 & 88 to 319 \\
Employed $\geqslant 5$ y & 8 & 2.5 & 326 & 140 to 643 \\
\hline
\end{tabular}

also found for those people first employed after 1950 and were significant for the group of insulators.

Several of the deaths from mesothelioma were originally coded as primary lung cancer deaths (an ICDA- 8 code of 162.9 for the underlying cause of death), and increased mortality from lung cancer has also been associated with exposure to asbestos. ${ }^{9}$ Table 1 also shows the SMRs for lung cancer with the mesothelioma deaths with an ICDA-8 of 162.9 excluded for the two exposure groups defined by duration of employment. Only the subcohort of insulators had a mortality that increased slightly with duration of employment in the group. None of these SMRs was significant. For the larger exposure group, the SMRs increase with duration of employment, but all are $<100$. There was a non-significant increase for lung cancer for those first employed as insulators before 1950 $(\mathrm{SMR}=159)$ but a large deficit for those first employed in 1950 and after $(S M R=60)$. No information on the smoking histories of the cohort was available.

MORTALITY ANALYSES OF BRAIN TUMOURS

There were 21 observed deaths and 15.5 expected from benign and unspecified brain tumours, resulting in an SMR of 135 (not significant). There were 64 observed deaths and 59.5 expected from cancer of the brain and central nervous system. Combining all such tumours gave 85 observed deaths and 75 expected, for an SMR of 113 (table 2). Observed and expected deaths from brain tumours were compared for persons employed in maintenance $(S M R=110)$; in receiving, pumping, and storage $(\mathrm{SMR}=101)$; as a pipefitter $(S M R=100)$; as laboratory staff $(S M R=166)$; and on the motor oil units $(\mathrm{SMR}=178)$. The total cohort SMRs for those first employed before 1950 and for those first employed in 1950 or later were the same $(S M R=113)$. Mortality from brain tumours for people employed either in laboratory jobs or on the motor oil units for $\geqslant 5$ years were higher than for people ever so employed, and the SMRs were significant $(S M R s=185$, and 326, respectively). 
Table 3 Texaco mortality study: SMRs for non-Hodgkin's lymphoma and multiple myeloma, white men, 1947-93

\begin{tabular}{|c|c|c|c|c|c|c|}
\hline & \multicolumn{3}{|c|}{ Non-Hodgkin's lymphoma } & \multicolumn{3}{|c|}{ Multiple myeloma } \\
\hline & Observed & $S M R$ & $95 \% C I$ & Observed & $S M R$ & $95 \% C I$ \\
\hline \multicolumn{7}{|l|}{ Total cohort: } \\
\hline Ever & 74 & 88 & 69 to 111 & 36 & 101 & 70 to 140 \\
\hline Employed before 1950 & 56 & 87 & 65 to 113 & 30 & 103 & 69 to 147 \\
\hline Employed 1950 and after & 18 & 95 & 56 to 151 & 6 & 91 & 33 to 199 \\
\hline \multicolumn{7}{|l|}{ Maintenance: } \\
\hline Ever & 54 & 87 & 65 to 114 & 30 & 112 & 76 to 161 \\
\hline \multicolumn{7}{|l|}{ Operators: } \\
\hline Ever & 37 & 73 & 51 to 101 & 17 & 79 & 46 to 126 \\
\hline \multicolumn{7}{|l|}{ Fluid catalytic cracking unit: } \\
\hline Ever & 13 & 155 & 82 to 265 & 7 & 198 & 79 to 408 \\
\hline Employed $\geqslant 5 \mathrm{y}$ & 6 & 118 & 43 to 258 & 6 & 270 & 98 to 589 \\
\hline \multicolumn{7}{|l|}{ Receiving, pumping and storage: } \\
\hline Ever & 14 & 118 & 64 to 198 & 6 & 118 & 43 to 258 \\
\hline \multicolumn{7}{|l|}{ Pipefitters, boilermakers } \\
\hline Ever & 15 & 72 & 40 to 119 & 14 & 153 & 84 to 258 \\
\hline \multicolumn{7}{|l|}{ Delayed coking unit: } \\
\hline Ever & 6 & 86 & 31 to 188 & 6 & 196 & 71 to 427 \\
\hline Employed $\geqslant 5 \mathrm{y}$ & & & & 1 & 156 & 2 to 873 \\
\hline \multicolumn{7}{|l|}{ Crude stills: } \\
\hline Ever & 16 & 122 & 70 to 199 & 9 & 155 & 70 to 294 \\
\hline Employed $\geqslant 5 y$ & & & & 5 & 172 & 55 to 401 \\
\hline
\end{tabular}

MORTALITY ANALYSES OF NON-HODGKIN'S LYMPHOMA

Table 3 shows the results of the analysis of deaths from non-Hodgkin's lymphoma. Observed and expected deaths from lymphosarcoma, reticulum cell sarcoma, and lymphoma combined were similar for the total cohort $(\mathrm{SMR}=88)$ and for those employed in maintenance (SMR $=87)$, in receiving, plumbing, and storage $(\mathrm{SMR}=118)$, on a process unit $(\mathrm{SMR}=73)$, on the delayed coking unit $(\mathrm{SMR}=86)$; on the crude unit $(\mathrm{SMR}=122)$; and as a pipefitter or boilermaker $(\mathrm{SMR}=72)$. The SMRs are similar for those first employed before 1950 (SMR=87) and first employed 1950 and after $(S M R=95)$. For those ever employed on the fluid catalytic cracking unit, the SMR was 155 , but it decreased to 118 for those employed on the fluid catalytic cracking unit $\geqslant 5$ years. None of these SMRs was significant.

MORTALITY ANALYSES OF MULTIPLE MYELOMA

Table 3 also shows the results of the analysis of multiple myeloma. The observed and expected deaths were about the same for the total cohort $(\mathrm{SMR}=101)$; people employed in maintenance (SMR =112); employed in receiving, plumbing, and storage $(S M R=118)$; and employed on a process unit $(\mathrm{SMR}=79)$. Similar results were

Table 4 Texaco mortality study, SMRs for leukaemia by cell type, white men, 1947-93

\begin{tabular}{lrrrr}
\hline & Observed & Expected & SMR & 95\% CI \\
\hline Total cohort: & & & & \\
$\quad$ Acute lymphocytic (ALL) & 5 & 4.9 & 101 & 32 to 235 \\
ALL, employed before 1950 & 5 & 3.8 & 133 & 42 to 311 \\
Chronic lymphocytic (CLL) & 15 & 18.6 & 80 & 45 to 133 \\
CLL, employed before 1950 & 13 & 15.8 & 82 & 43 to 140 \\
CLL, employed 1950 and after & 2 & 2.8 & 72 & 8 to 262 \\
Acute myelogenous (AML) & 20 & 15.5 & 129 & 78 to 199 \\
AML, employed before 1950 & 19 & 12.2 & 155 & 93 to 243 \\
AML, employed 1950 and after & 1 & 3.3 & 30 & 0 to 168 \\
Chronic myelogenous (CML) & 12 & 11.4 & 105 & 54 to 183 \\
CML, employed before 1950 & 10 & 8.6 & 116 & 55 to 214 \\
CML, employed 1950 and after & 2 & 2.8 & 70 & 7 to 254 \\
Acute unspecified (AUL) & 15 & 5.4 & 276 & 154 to 455 \\
AUL, employed before 1950 & 13 & 4.7 & 276 & 147 to 472 \\
AUL, employed 1950 and after & 2 & 0.7 & 273 & 30 to 986 \\
Cell type unspecified (UL) & 15 & 6.5 & 231 & 129 to 381 \\
UL, employed before 1950 & 14 & 5.3 & 262 & 143 to 440 \\
UL, employed 1950 and after & 1 & 1.1 & 87 & 1 to 486 \\
\hline
\end{tabular}

seen for those first employed before 1950 $(\mathrm{SMR}=103)$ and first employed in 1950 and after $(S M R=91)$. For those employed on the fluid catalytic cracking unit, the SMR was 198 , and it rose to 270 for those employed on the fluid catalytic cracking unit $\geqslant 5$ years. For those employed on the crude unit, the SMR was 155 , increasing to 172 for those employed on the crude still $\geqslant 5$ years. Four of the decedents were employed on both the fluid catalytic cracking unit and the crude unit. For those employed as a pipefitter or boilermaker, the SMR was 153; however, there were no deaths from multiple myeloma among people employed as pipefitters or boilermakers for $\geqslant 5$ years. For those employed on the delayed coking unit the SMR was 196, but there was only one death among those employed on the delayed coking unit for $\geqslant 5$ years. These SMRs for multiple myeloma were not significant.

MORTALITY ANALYSES OF LEUKAEMIA BY CELL

TYPE

The SMRs were calculated for the cell type specific leukaemias where there are at least four deaths (table 4) for the total cohort and for those first employed before and after 1950. All but one of the cell type groups showed deficits in the group first employed in 1950 and after. The mortality for acute lymphocytic leukaemia was the same as expected (SMR=101), and all of the acute lymphocytic leukaemia deaths occurred in people first employed before 1950 $(\mathrm{SMR}=133)$. There was a deficit for chronic lymphocytic leukaemia $(S M R=80)$ with 13 of those deaths occurring in people first employed before $1950 \quad(\mathrm{SMR}=82)$ and two in those employed in 1950 and after $(\mathrm{SMR}=72)$.

The SMR for acute myelogenous leukaemia was 129 . Nineteen of the 20 deaths occurred in people first employed before 1950 $(S M R=155)$, and there was a deficit among people first employed in 1950 and after $(\mathrm{SMR}=30)$. Mortality from chronic myelogenous leukaemia was essentially the same as expected $(\mathrm{SMR}=105)$. Ten of the 12 deaths occurred in people first employed before 1950 $(\mathrm{SMR}=116)$, and there was a deficit of chronic 
myelogenous leukaemia among people first employed in 1950 and after $(S M R=70)$.

There were significant excesses for acute leukaemia, unspecified $(S M R=276)$, and for leukaemia cell type unspecified $(S M R=231)$. For acute leukaemia, unspecified, the SMR was essentially the same among people first employed before 1950 and those first employed in 1950 and after $(S M R s=276$ and 273 respectively). For leukaemia, cell type unspecified, the SMR was increased for those first employed before 1950 (SMR=262), but for those first employed in 1950 and after, there was a deficit $(\mathrm{SMR}=87)$.

\section{Discussion}

There was a significant increase in mortality from mesothelioma for the total cohort which was higher for people employed in maintenance subgroups based on their potential for exposure to asbestos. Although the increase was highest for people employed as insulators, mortality rose in all of the maintenance groups with increasing employment in that group. An examination of mortality by time first employed showed that the SMRs were highest for people first employed in any of the subgroups before 1950. Almost all of the cohort's increased mortality from mesothelioma was limited to the maintenance subgroups, especially insulators. There were only seven deaths from mesothelioma versus 5.3 expected $(S M R=130)$ for those never employed in the maintenance subgroup and only two versus 3.9 $(\mathrm{SMR}=51)$ for those never employed in any maintenance job.

The finding of excess mortality from mesothelioma in this cohort was not unexpected. Materials containing asbestos were used in the past as thermal insulation for various vessels and pipes in refineries. There were no industrial hygiene sampling data about the levels of exposure to asbestos for the various crafts until the 1970s, and by that time work practices for asbestos handling had already been modified. However, insulators would have had the highest potential for exposure, followed by workers in other crafts who had to work with insulation to accomplish their tasks.

Several other petroleum industry studies have also shown increased mortalities for mesothelioma in refinery workers. ${ }^{2-5}$ Other studies of refinery workers have not identified excess deaths from mesothelioma. Collingwood et $a l^{13}$ found two deaths from mesothelioma versus 2.3 expected at the Mobil Paulsboro refinery, and Raabe et $a l^{14}$ found one death from mesothelioma versus 3.2 expected at the Mobil Beaumont refinery.

Although mesothelioma is known to be associated with asbestos exposure in the shipbuilding industry, ${ }^{6}$ it is unlikely that much of the excess found in this cohort was associated with exposures in this industry during the second world war. No information on previous employment was available. However, even if all people who had the potential to be employed in shipbuilding during the second world war were excluded, the SMRs are still significantly increased.
Because of the lack of mortalities for mesothelioma and of a specific ICD code for this cause of death, the comparability of the mesothelioma SMRs among all these studies is unknown other than with the study by Tsai et $a .^{2}$ Our comparison mortalities were the same as those used in that study as was the definition of the maintenance subgroup. It is unknown why some of the refinery studies show lower than expected SMRs for mesotheliomas.

No increase in mortality from lung cancer was found in the larger maintenance subgroup. There was, however, a small increase in lung cancer mortality for those employed as insulators which rose with increasing duration of employment. The increases were small and not significant. There was a deficit of lung cancer mortality among those first employed in 1950 and after for both groups. No histories on smoking were available to indicate whether these increases were primarily found in smokers.

The SMR for all brain tumours for the total cohort (113) was similar to that reported for cancer of the brain and central nervous system (108) in the earlier report. ${ }^{1}$ The highest SMRs for all brain tumours combined were 178 for people ever employed on any of the motor oil units and 326 for people employed on these units for $\geqslant 5$ years. These results were similar to those for cancer of the brain and central nervous system where the SMRs were 164 and 314, respectively. An SMR for brain tumours of 166 was found for people ever employed in research or quality control laboratories and it was 185 for people employed as laboratory staff for $\geqslant 5$ years. Again, these SMRs were similar to those for cancer of the brain and central nervous system where the SMRs were 142 and 169, respectively. Thus, other than increasing the number of deaths, combining all brain tumours together did not change the pattern of results found for the category of cancer of the brain and central nervous system alone.

There were no specific chemical exposures that might be common to the motor oil unit and the laboratory, and that have been associated with brain tumours. In any event, laboratory practices have changed dramatically over the past 30 years and exposure potentials have declined steadily through the automation of test procedures and advances in the design of laboratory ventilation. Similar decreases in exposure levels have also been achieved on operating units through the use of engineering controls and enhanced work practices.

With Texas death rates as the comparison, Satin et $a \bar{l}$ found an increase in benign and unspecified brain tumours at the Gulf/Chevron Port Arthur refinery. The SMR was much lower when United States death rates were used. A previous report on brain tumours in the Port Arthur refinery cohort ${ }^{15}$ discussed the problems associated with diagnostic errors of brain tumours. Errors occur more often among inaccessible tumours - such as those occurring in the liver, brain, or pancreas. A potential for more accurate and complete reporting of brain tumours in occupational groups as a result of diagnostic sensitivity bias has also been dis- 
cussed in several previous investigations. ${ }^{16-18}$ Diagnostic sensitivity bias is one reasonable explanation for the increased SMR of 113 for brain tumours for the overall Texaco mortality study cohort.

The causes of malignant and benign brain tumours are still largely unknown. ${ }^{19}$ Within the general population of the United States, the recorded cases of, and deaths from, cancers of the brain and central nervous system have been rising slightly since the $1970 \mathrm{~s} .{ }^{20}$ Some or all of these increases are thought to result from the advent of computed tomography, magnetic resonance imaging, and other techniques that have led to improvements in the detection of previously undiagnosed or misdiagnosed cases of brain tumours.

The few established risk factors for brain tumours account for only a small proportion of cases. Genetics plays a part, ${ }^{21}$ and ionising radiation to the head is a strong, but rare, risk factor. $^{22} 23$ The only occupational exposure linked to increased risk of brain cancer is exposure to high concentrations of vinyl chloride, ${ }^{24}$ which was not present at any of the Texaco mortality study locations. For dozens of occupational groups, slight, inconsistent excess risks of brain cancer have been reported by various investigators, but no convincing associations, certainly not specific causative agents, have been identified. ${ }^{19}$

The analysis of the SMRs for non-Hodgkin's lymphoma for the total cohort and for the job and process unit groups shows primarily deficits and slight increases. The only job group with a noticeable increase for nonHodgkin's lymphoma is the fluid catalytic cracking unit $(\mathrm{SMR}=155)$, but the SMR decreases to 118 for those employed on the fluid catalytic cracking unit for $\geqslant 5$ years. Thus, the increased SMRs found in the previous report ${ }^{1}$ for cancer of other lymphatic tissue among people employed on the fluid catalytic cracking unit or the crude stills were not related to increased mortality from non-Hodgkin's lymphoma.

However, the SMR for multiple myeloma for people ever employed on the fluid catalytic cracking unit was 198 , and it increased to 270 for those people with $\geqslant 5$ years on this unit. For people ever employed on a crude unit, the SMR was 155 , increasing to 172 for those people with $\geqslant 5$ years on this unit. The increases for the groups employed for $\geqslant 5$ years in the job are based on only six and five deaths, respectively, and some of these were employed on both units.

The SMR for multiple myeloma among those employed on the delayed coking unit for $\geqslant 5$ years was lower than for the 1 year group, and there were no deaths from multiple myeloma in the group of pipefitters and boilermakers employed for $\geqslant 5$ years. There were no specific exposures associated with employment on the fluid catalytic cracking unit or crude stills which have been associated with multiple myeloma. Also, there was no evidence that multiple myeloma was increased in petroleum workers overall. Wong and Raabe ${ }^{25}$ carried out a meta-analysis of multiple myeloma in a mul- tinational cohort of over 250000 petroleum workers. The SMR for multiple myeloma was 93, and there was no pattern by duration of observation.

The analysis of leukaemia by cell type showed a non-significantly increased SMR for acute myelogenous leukaemia for white men overall, which was limited to those people first employed before 1950. Because many of the deaths from leukaemia do not have a specific cell type mentioned on the death certificate, this resulted in significant excesses of both acute leukaemia and leukaemia, cell type unspecified. More detailed information about the specific cell type of leukaemia would reduce the increases in the unspecified categories, and increase the SMRs in some or all of the categories specific for cell type. However, although death certificates are considered to be highly accurate in their diagnosis of leukaemia, ${ }^{26}$ the accuracy of the information specific to cell type is much lower. It would be better to have access to hospital and pathological information, but that is not possible in a study of this type. A meta-analysis of leukaemia by cell type in workers in the petroleum industry ${ }^{4}$ did not show increased SMRs for acute myelogenous leukaemia or any of the other leukaemia cell types.

Although employees' complete work histories were used for these cause specific analyses, information about the specific chemicals associated with each of the job and unit combinations was not available, nor was there any industrial hygiene sampling data covering the first 30 years of the study. (For information about potential exposures associated with the jobs and units, see table 1 in the previous report ${ }^{1}$.) Jobs and units with similar responsibilities were grouped together for the analyses as a surrogate for exposures, but provided little information to link exposure and outcome.

Patterns of mortality were examined by time first employed to determine if the patterns had changed over time. Although many groups showed much lower SMRs for those more recently employed, in many cases the number of observed deaths was so small that the results were difficult to interpret.

\section{Conclusion}

Further analyses of specific causes of death by duration of employment in various job and process units did not show any patterns which would suggest that, other than for mesothelioma, any of these increases in mortalities were likely to result from either workplace exposures or employment at one of the locations included in the Texaco mortality study. The brain tumour rates in people employed in the motor oil units and the laboratories and the rates for multiple myeloma in those employed on the fluid catalytic cracking units rose with increasing duration of employment in these jobs. However, there was no known exposure common to these jobs which had been associated with brain cancer or multiple myeloma, nor has an increased risk of these causes of death been consistently found in other studies of petroleum workers. There was 
only a slight and non-significant increase in the SMR for acute myelogenous leukaemia which is the only leukaemia cell type associated with benzene exposure. The increase in mesotheliomas has been found in other studies of refinery workers, and it rose steadily with duration of employment. The rate for mesothelioma was higher among those first employed $>45$ years ago and those employed in job groups with greater potential for exposure to asbestos.

1 Divine BJ, Hartman CM, Wendt JK. An updated report on the Texaco mortality study 1947-1993 Part I. Analysis of of mortality Occup Environ Med 1999;56:167-73

2 Tsai SP, Waddell LC, Gilstrap EL, et al. Mortality among maintenance employees potentially exposed to asbestos in a refinery and petrochemical plant. Am f Ind Med 1996;29: 89-98.

3 Wong O. Risk of acute myeloid leukaemia and multiple myeloma in workers exposed to benzene. Occup Environ Med 1995;52:380-4.

4 Wong O, Raabe GK. Cell-type specific leukemia analyses in a combined cohort of more than 208,000 petroleum workers in the United States and the United Kingdom. Reg Toxicol Pharmacol 1995;21:307-21.

5 Satin KP, Wong O, Yuan LA, et al. A 50-year mortality follow-up of a large cohort of oil refinery workers in Texas. f Occup Environ Med 1996;38:492-506.

6 Fraumeni JF, Blot W. Lung and pleura. In: Schottenfeld D, Fraumeni JF, eds. Cancer epidemiology and prevention. Philadelphia: WB Saunders, 1982:564-82.

7 Marsh GM, Ehland J, Sefcik S. Mortality and population data system (MPDS). Pittsburgh, PA: University of Pittsburgh, Department of Biostatistics Technical Report, 1987

8 Monson RR. Analysis of relative survival and proportionate mortality. Comput Biomed Res 1974;7:325-32.

9 Doll R, Peto R. The causes of cancer. New York: Oxford University Press, 1981:1243.

10 Schnatter AR, Theriault G, Katz AM, et al. A retrospective mortality study within operating segments of a petroleum mortality study within operating segment
company. Am 7 Ind Med 1992;22:209-29.

11 Kaplan SD. Update of a mortality study of workers in petroleum refineries. F Occup Med 1986;28:514-6.
12 Hornstra M. A mortality study of Whiting refinery employees. Chicago, IL: Report for Amoco Corporation, 1993.

13 Collingwood KW, Raabe GK, Wong O. An updated cohort mortality study of workers at a northeastern United States petroleum refinery. Int Arch Occup Environ Health 1996;68: 277-88.

14 Raabe GK, Collingwood KW, Wong O. An updated mortality study of workers at a petroleum refinery in Beaumont, TX. Am f Ind Med 1998;33:61-81.

15 Wen CP, Tsai SP, Gibson RL. A report on brain tumors from a retrospective cohort study of refinery workers. Ann NY Acad Sci 1981;381:130-8.

16 Greenwald P, Friedlander BR, Lawrence CE, et al. Diagnostic sensitivity bias: an epidemiologic explanation for an apparent brain tumor excess. F Occup Med 1981;23: $690-4$.

17 Wong O, Morgan RW, Bailey WJ, et al. An epidemiological study of petroleum refinery workers. Br F Ind Med 1986;43: 6-17.

18 Wong O, Whorton MD. Diagnostic bias in occupational epidemiologic studies: an example based on the vinyl chloride literature. Am f Ind Med 1993;24:251-6.

19 Inskip PD, Linet MS, Heineman EF. Etiology of brain tumors in adults. Epidemiol Rev 1995;15:382-414.

20 Ries LAG, Kosary CL, Hankey BF, et al, eds. SEER cancer statistics review 1973-94. Bethesda, MD: National Cancer Institute, 1997. (NIH publ no 97-2789).

21 Chung RY, Seizinger BR. Molecular genetics of neurological tumors. F Med Genet 1992;29:361-7.

22 Ron E, Modan B, Boice JD Jr, et al. Tumors of the brain and central nervous system after radiotherapy in childhood. $N$ Engl f Med 1988;319:1033-9.

23 Neglia JP, Meadows AT, Robison LL, et al. Second neoplasms after acute lymphoblastic leukemia in childhood. N Engl F Med 1991;325:1330-6.

24 International Agency for Research on Cancer. IARC Monographs of the evaluation of the carcinogenic risk of chemicals to humans. Overall evaluations of carcinogenicity: an updating of IARC monographs. Vols 1-42, suppl 7. Lyon, France: International Agency for Research on Cancer, 1987.

25 Wong O, Raabe GK. Multiple myeloma and benzene exposure in a multinational cohort of more than 250,000 petroleum workers. Reg Toxicol Pharmacol 1997;26:188-99.

26 Percy C, Stanek III E, Gloeckler L. Accuracy of cancer death certificates and its effect on cancer mortality statistics. Am f Public Health 1981;71:242-50. 